\title{
Residents Achieve a High Patient Satisfaction in Pre-Anesthetic Patient Assessment. An Observational Study
}

\author{
Ulrike Reuter ${ }^{1}$, Babette Jurack1, Nils Engelmann' ${ }^{2}$, Thilo Busch ${ }^{1}$, Joerg Schnoor ${ }^{{ }^{*}}$ \\ ${ }^{1}$ Department of Anesthesiology and Intensive Care Medicine, University Hospital Leipzig, Leipzig, Germany \\ ${ }^{2}$ Department of Anaesthesiology, King's College Hospital Clinics, Abu Dhabi, UAE \\ Email: ${ }^{*}$ joerg.schnoor@medizin.uni-leipzig.de
}

Received 16 September 2014; revised 16 October 2014; accepted 31 October 2014

Academic Editor: Piacherski Valery, Mogilev Regional Hospital, Belarus

Copyright (C) 2014 by authors and Scientific Research Publishing Inc.

This work is licensed under the Creative Commons Attribution International License (CC BY). http://creativecommons.org/licenses/by/4.0/

(c) (i) Open Access

\section{Abstract}

A physician's empathetic attitude is regarded as an important influencing factor towards patient satisfaction. However, physicians' self-assessed empathy declines during medical school and through residency, which may limit patient satisfaction in the doctor-patient contact. In consequence, we hypothesized that residents might fail in generating high levels of patient satisfaction. We conducted an observational study in the setting of a pre-anesthetic assessment center, University Hospital Leipzig, Germany. Patient satisfaction was measured using the overall ZUF-8 score (8 32 points; increasing with patient satisfaction). Data were collected by questionnaires (ZUF-8 items, additional satisfaction items, and items of organizational and logistical processes). Key items for patient satisfaction as primary endpoints were defined. Statistical evaluation was performed in dependency of the anesthesiologists' level of training (residents vs. consultants) by using the Mann-Whitney-U test or the chi square test, as required. Statistical significance was accepted for $p<0.05$. In total, 2565 patients were assessed for eligibility. 986 patients met the criteria of inclusion. 978 questionnaires were submitted with 517 questionnaires being excluded because of missing values. Finally, 461 questionnaires could be analysed. Both residents and consultants achieved a high level of patient satisfaction. The ZUF-8-scores were comparable between the groups $(p=0.91)$, whilst the quality of consultation was rated slightly better by patients being assessed by residents $(p=0.047)$. The results in additional satisfaction items were comparable between the groups. We found a trend in residents assessing to be rated more friendly. Residents are able to generate a high level of patient satisfaction which is comparable to that of consultants with scores ranging between "good" and "very good". Small albeit significant differences in favor of residents underline the quality of their performance in pre-anesthetic patient assessment.

\footnotetext{
${ }^{*}$ Corresponding author.
}

How to cite this paper: Reuter, U., Jurack, B., Engelmann, N., Busch, T. and Schnoor, J. (2014) Residents Achieve a High Patient Satisfaction in Pre-Anesthetic Patient Assessment. An Observational Study. Open Journal of Anesthesiology, 4, 263275. http://dx.doi.org/10.4236/ojanes.2014.411039 


\section{Keywords}

\section{Patient Satisfaction, Pre-Anesthetic Patient Education, ZUF-8 Questionnaire, Physicians' Educational Level}

\section{Introduction}

In the future, patient satisfaction will gain a greater role in quality assessment in healthcare. Patients do not only function as recipients of medical treatment, but are actively involved in their individual healing processes. It seems self-evident that a high level of patient satisfaction may increase compliance and thus show beneficial effects on clinical outcome [1] [2].

There are only few data concerning patient satisfaction in the area of a pre-anesthetic assessment center. The contact between patient and anesthesiologist is of potential impact on satisfaction [3]. Whilst high levels of patient satisfaction are particularly based on the empathy of the care givers [4]-[6], physicians' self-assessed empathy seems to decline during residency, which might be due to an increase in daily distress during their clinical practice phase [7] [8].

Consequently, residents deployed in German pre-anesthetic assessment centers might be expected to fail in generating high levels of patient satisfaction. Hence, in the manner of an observational study design, a German concise version of a validated multi-item patient questionnaire (American CSQ-8, 17 items) was used to investigate patient satisfaction with regards to the physicians' level of training [9] [10]. The German questionnaire (ZUF-8, 8 items) has been shown to measure patient satisfaction in a reliable and economical manner by using a four-point Likert scale [11].

\section{Methods}

This study was approved by the local ethics committee. All patients were informed about their voluntary and anonymous participation; written informed consent was obtained. The data collection took place in a pre-anesthetic assessment center at the University Hospital Leipzig, Germany, over a period of nine weeks. This clinic represents a tertiary hospital with about 120 anesthesiologists. Approximately 25,000 anesthetics/year are performed for both in- and outpatients in all surgical departments except cardiac surgery.

All adults within the ASA classification I - IV were included. Exclusion criteria were age under 18 years, a lack of capacity to consent, inadequate language skills, prior participation in the study (e.g. as part of revision surgery), patient consultations on wards (e.g. emergencies, infectious or bedbound patients), and refusal to participate.

\subsection{Questionnaires}

In order to evaluate patient satisfaction we used a validated multi-item questionnaire (ZUF-8 questionnaire; the German adaptation to the American CSQ-8 questionnaire (Table 1) [9]-[12]). In addition, newly defined verbal items were used to determine additional factors influencing patient satisfaction as well (Table 2 and Table 3 ). Both a pre-questionnaire and a post-questionnaire had, therefore, to be filled out by each patient before and after consultation.

\subsection{ZUF-8 Questionnaire}

The eight-item comprehensive ZUF-8 questionnaire is an economic self-assessment measuring instrument for global, one-dimensional registration of patient satisfaction (Table 1) [13]. The ZUF-8 items are poled from 1 - 4 whereas 1 refers to the lowest and 4 to the highest level of satisfaction. Out of their sum an overall ZUF-8 score is generated (scale range 8 - 32). According to Hannöver et al. [14] values of at least 24 are regarded as an indicator of satisfaction ( 8 = dissatisfied, 16 = less satisfied, 24 = largely satisfied, 32 = very satisfied).

\subsection{Additional Satisfaction Items}

Moreover, we considered 15 additional satisfaction items. Therefore, further aspects of satisfaction were eva- 
luated by items scaled with the "Likert scale" with four response options (without any neutral position) and a uniform direction of the response format (from 1 = lowest satisfaction, to $4=$ highest satisfaction) (Table 2). Additional nominal response options were recorded for the items "questions answered completely" and "attitude towards anesthesia and surgery before/after consultation”.

\subsection{Process Chains}

Organizational and logistical processes and their effects on patient briefing and satisfaction were documented (Table 3). Here, particular attention was paid to whether all necessary information about the patient was availa-

Table 1. Overall satisfaction with the anesthetic pre-assessment, determined by a modified questionnaire, adapted to the preassessment center (ZUF-8 [11]).

1) To what extend has the anesthetic pre-assessment center catered for your need?

( 4 = catered for almost all my need; 3 = catered for most of my need; 2 = catered for just a few of my need; 1 = has not catered for my need)

2) How would you rate the quality of your anesthetic consultation?

(4 = excellent; 3 = good; 2 = not so good; 1 = bad)

3) How satisfied were you with the overall content of your pre-assessment?

(4 = satisfied; 3 = mostly satisfied; 2 = with reservations; 1 = not satisfied)

4) Has the anesthetics consultation helped you to revaluate your concerns regarding the anesthetics procedure?

( 4 = yes, it has been very helpful; 3 = it helped a little; 2 = it did not help at all; 1 = no, it made it even more difficult to deal with)

5) Would you opt for this anesthetics department again if you had to undergo other anesthetics?

(4 = definitely; 3 = generally speaking, yes; 2 = generally speaking, no; 1 = absolutely not)

6) Would you recommend the anesthetic department to a friend if he or she needed an anesthetic?

(4 = definitely; 3 = generally speaking, yes; 2 = generally speaking, no; 1 = absolutely not)

7) Would you come back to the University Hospital Leipzig if you were in need of medical attention?

(4 = definitely; 3 = generally speaking, yes; 2 = generally speaking, no; 1 = absolutely not)

8) Would you recommend the University Hospital Leipzig to a friend if he or she needed medical attention?

(4 = definitely; 3 = generally speaking, yes; 2 = generally speaking, no; 1 = absolutely not)

The sum of achieved points leads to the overall ZUF-8 score (scale range (min - max): 8 - 32). KAI: Department of Anesthesiology.

Table 2. Additional satisfaction items.

Recommendation of UKL

Return to UKL

Attitude towards anesthesia before consultation

Attitude towards anesthesia after consultation

Attitude towards surgery before consultation

Attitude towards surgery after consultation

Worry about surgery

Friendliness

Advice

Details understood

Adequate consulting time

Questions answered completely

Clear language

Fully understood

Delay

There were additional nominal response options for the items "questions answered completely" and "attitude towards anesthesia and surgery before/after consultation”; UKL: University Hospital Leipzig. 
ble to the responsible anesthesiologist at the time of pre-anesthetic assessment. Patient's waiting period and consulting time were recorded as well.

\subsection{Biometric and Medical Data}

Biometric data (i.e. age, gender, BMI (Body Mass Index), education) and medical patient characteristics (i.e. surgical informed consent, in-/outpatient, ASA-classification, previous anesthesia, planned anesthesia procedures) were gathered (Table 4).

Table 3. Items for organizational and logistic processes.

$$
\begin{gathered}
\text { Estimated type of surgery } \\
\text { Estimated time of surgery } \\
\text { Case history } \\
\text { Examination findings } \\
\text { Waiting period } \\
\text { Consulting time }
\end{gathered}
$$

\begin{tabular}{|c|c|c|c|}
\hline Items & Residents & Consultants & p value \\
\hline n (patients) & 370 & 91 & \\
\hline Age (years) & $52.5 \pm 16.5[50.1 ; 53.7]$ & $52.2 \pm 16.5[48.4 ; 55.5]$ & 0.875 \\
\hline Gender & & & 0.488 \\
\hline Male & 202 (54.6\%) & 46 (49.5\%) & \\
\hline Female & 168 (45.4\%) & 45 (50.5\%) & \\
\hline BMI $\left(\mathrm{kg} / \mathbf{m}^{2}\right)$ & $27.1 \pm 5.6[26.3 ; 27.4]$ & $27.3 \pm 6.8[25.6 ; 28.5]$ & 0.709 \\
\hline Surgical informed consent & & & 0.750 \\
\hline Yes & $314(84.9 \%)$ & $76(83.5 \%)$ & \\
\hline No & $56(15.1 \%)$ & $15(16.5 \%)$ & \\
\hline Outpatient. inpatient & & & 0.723 \\
\hline Outpatient & $163(44.8 \%)$ & $38(42.7 \%)$ & \\
\hline Inpatient & $201(55.2 \%)$ & $51(57.3 \%)$ & \\
\hline $\begin{array}{c}\text { Time of surgery knowledge } \\
\text { Yes } \\
\text { No }\end{array}$ & $\begin{array}{c}318(86.2 \%) \\
51(13.8 \%)\end{array}$ & $\begin{array}{l}67(73.6 \%) \\
24(26.4 \%)\end{array}$ & 0.004 \\
\hline ASA classification & II (I - III) & II (I - III) & 0.462 \\
\hline Previous anesthesia & & & 0.338 \\
\hline Yes & 325 (88.3\%) & 77 (84.6\%) & \\
\hline No & $43(11.7 \%)$ & $14(15.4 \%)$ & \\
\hline Planned anesthesia procedures & & & 0.992 \\
\hline General anesthesia & $302(88.1 \%)$ & 76 (89.4\%) & \\
\hline Spinal or epidural anesthesia & $21(6.1 \%)$ & $5(5.9 \%)$ & \\
\hline Peripheral neuronal block & $7(2.0 \%)$ & $1(1.2 \%)$ & \\
\hline Others & 13 (3.8\%) & $3(3.5 \%)$ & \\
\hline
\end{tabular}

There were items for organizational and logistic processes. Key items: KAI: Department of Anesthesiology; UKL: University Hospital Leipzig; BMI: Body Mass Index; ASA: American classification of Anesthesiologists.

Table 4. Biometric and medical patient characteristics.

We listed data in dependency of the groups compared (residents vs. consultants). Absolute numbers with proportions (\%) for nominal variables, and mean value with standard deviation (SD), median value with minimum-maximum for ASA-classification, and 95\% confidence intervals (CI) for numerical variables, respectively, are given. We considered p values $<0.05$ significant. The response option "others" in the item "planned anesthesia procedures" refers to combined anesthesia procedures of general and regional anesthesia. BMI: Body Mass Index; ASA: American Society of Anesthesiologists. 


\subsection{Sample Size}

With a statistical power of $80 \%$ and a supposed mean difference of $10 \%$ in patient satisfaction, 237 patients per group should be included in the study.

\subsection{Statistical Analysis}

After collection, data were transferred to a spreadsheet program (Excel ${ }^{\circledR}$, Windows XP). We defined key items for patient satisfaction (ZUF-8), age, gender BMI, ASA, surgical patient education (informed consent), the anesthesiologists' educational level, waiting period, and consulting time as primary endpoints (Table 5). The statistical calculations were performed by using SPSS ${ }^{\circledR}$ (version 20, IBM ${ }^{\circledR}$ ). Numerical and ordinal variables were analyzed using the Mann Whitney U test. Nominal data were compared between groups using the chi square test or Fisher's exact test, as required. In the text, data were given as mean \pm standard deviation (SD) with 95\% confidence interval (CI), or as number and proportion. Statistical significance was accepted for $\mathrm{p}<$ 0.05 .

\section{Results}

2565 patients received pre-anesthetic patient briefing during the data collection period. Out of these, 986 patients could be included in the study and obtained a questionnaire. 978 questionnaires were returned. This cor-

Table 5. Key items.

ZUF-8 items

Additional satisfaction items

Process chains

Biometric and medical data

\author{
Quality of consultation \\ Kind of consultation \\ Patient's needs \\ Recommendation of KAI \\ Content of consultation \\ Worry about anesthesia \\ Satisfaction in general \\ Return to KAI
}

Recommendation of UKL

Return to UKL

Attitude towards anesthesia before consultation

Attitude towards anesthesia after consultation

Attitude towards surgery before consultation

Attitude towards surgery after consultation

Worry about surgery

Anesthesiologists' educational level

Waiting period

Consulting time

Age

Gender

BMI

Surgical informed consent 
responds to a response rate of 99.2\%. However, 517 questionnaires (52.9\%) showed missing values. Thus, 461 questionnaires remained to be evaluated statistically.

The two groups being compared differed in the number of patients analyzed, and in the number of physicians involved. 370 patients were assessed by 28 residents, while 91 patients were consulted by 33 consultants.

\subsection{ZUF-8 Questionnaire}

Both residents and consultants achieved a high level of patient satisfaction. Values ranged from 16 to 32 whereas $98.9 \%$ of the participants were located in the value area between 24 and 32 (Figure 1). The mean of the overall ZUF-8 score was $29.2 \pm 2.7$ [95\% CI $=28.9$, 29.3]. The ZUF-8-scores were comparable between the groups (residents $29.2 \pm 2.6$ [95\% CI = 28.9, 29.4]; consultants $29.0 \pm 3.1$ [95\% CI = 28.4, 29.8]; p = 0.91) (Figure 2). The quality of consultation was rated slightly better by patients being assessed by residents $(\mathrm{p}=$ 0.047). Here, the residents achieved slightly higher scores of satisfaction ( $3.6 \pm 0.5$ [95\% CI = 3.5, 3.6]), whem compared to consultants $(3.4 \pm 0.5[95 \% \mathrm{CI}=3.3,3.5])$.

\subsection{Additional Satisfaction Items}

Results in additional satisfaction items were comparable between the groups. We found a trend in assessing residents to be more friendly $(\mathrm{p}=0.09)$ (Figure 3).

\subsection{Process Chains}

Data of organizational and logistical processes showed some significant differences in cases of pre-operative examination findings and estimated time of sugery. Pre-operative examination findings were almost twice as often available among consultants (63.3\%) when compared to residents (34.5\%; $\mathrm{p}<0.001)$. In contrast, the estimated time of surgery was more often known by residents ( $86.2 \%$ vs. consultants $73.6 \%$; $p=0.004)$. The knowledge of patients's case history were comparable between the groups (residents $95.4 \%$ vs. consultants $98.9 \%$; $\mathrm{p}$ $=0.098$ ).

We found no differences in waiting time (residents 54.8 minutes \pm 33.3 [95\% CI $=51.4,58.2]$ vs. consultants 59.4 minutes $\pm 47.6[95 \% \mathrm{CI}=49.3,69.3]$; $\mathrm{p}=0.239$ ), time for briefing (residents 16.3 minutes $\pm 9.0[95 \% \mathrm{CI}=$

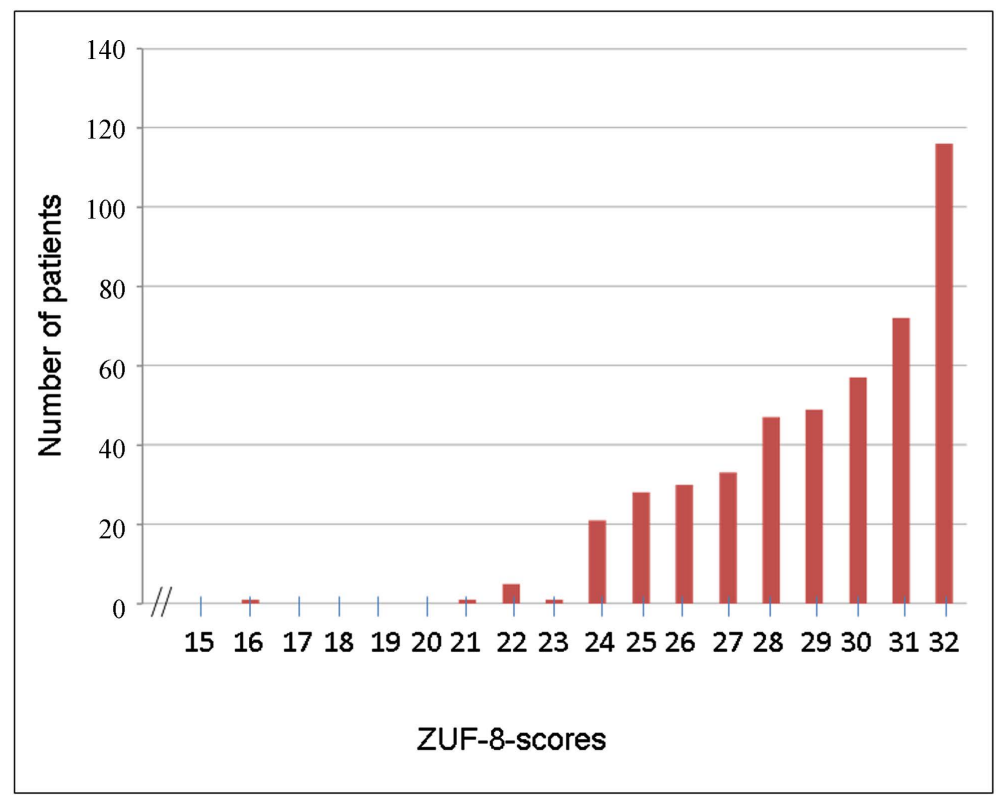

Figure 1. Distribution within the overall ZUF-8 score. The frequency distribution of the overall ZUF-8 score (min - $\max =8$ - 32) for both groups is illustrated. Overall scores of at least 24 are regarded as an indicator of satisfaction. 


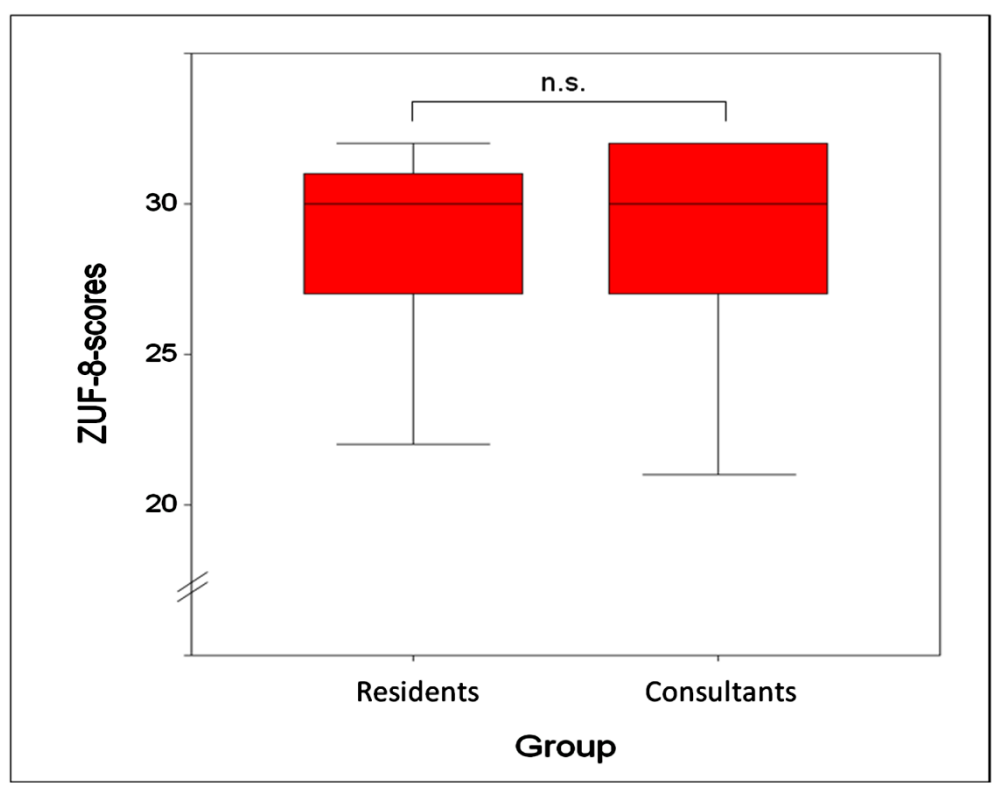

Figure 2. The overall ZUF-8 score. The overall ZUF-8 score in dependency of the groups compared (residents vs. consultants) is illustrated. Data are presented as box plot with medians, $25 \%$ and $75 \%$ percentiles. Characteristic score values are as follows: 8 = dissatisfied; 16 = less satisfied; 24 = largely satisfied; 32 = very satisfied. All score value were greater than 15 . We found no significant differences (n.s.) between residents and consultants.

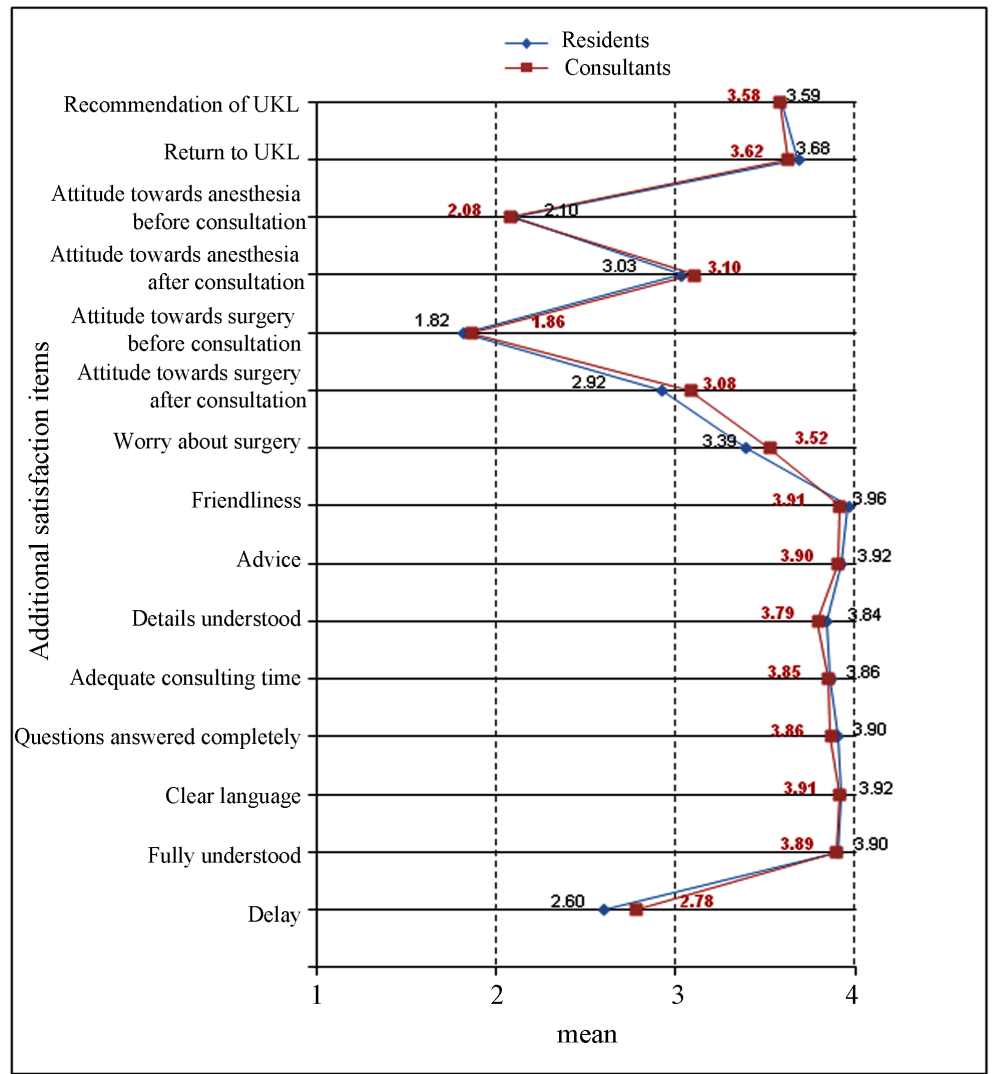

Figure 3. Additional satisfaction items. The mean values of the additional satisfaction items for residents and consultants are illustrated. Higher scores correspond to increased satisfaction ( 1 = dissatisfied, 2 = less satisfied, $3=$ largely satisfied, $4=$ very satisfied). We found no statistical significant differences between the groups. KAI: Department of Anesthesia; UKL: University Hospital Leipzig. 
15.3, 17.2] vs. consultants 16.9 minutes \pm 9.1 [95\% CI = 14.9, 18.7]; $\mathrm{p}=0.934$ ), and patients indicated delay (i.e. too long waiting periods) in the pre-anesthetic assessment center (residents $2.4 \pm 1.1[95 \% \mathrm{CI}=2.3,2.5]$ vs. consultants $2.2 \pm 1.1$ [95\% CI $=2.0,2.4] ; \mathrm{p}=0.556$ ) between the groups.

\subsection{Biometric and Medical Data}

There were no differences with respect to biometric and medical patient characteristics between the investigated groups of residents and consultants. About every second patient had completed a vocational training and every third patient graduated from high school or had a University degree. The remaining $20 \%$ had a school education of 9 to 10 years $(p=0.887)$.

\section{Discussion}

Satisfaction scores for both residents and consultants were generally high and located between "good" and "very good". These data offer first evidence that there were no significant differences in patient satisfaction after preanesthetic assessments when compared between physicians with different educational level of training.

The measurement of patient satisfaction is increasingly gaining importance in the context of quality management. Here, it is important to establish what constitutes quality of care from the perspective of patients, as well as having the views of clinicians and health care managers, as views differ [15]. Today, there are few data available concerning patient satisfaction with pre-anesthetic assessment. Aust et al. showed that the use of a preanesthesia assessment clinic in anesthetic patient care was not favorable from the patients' point of view. Getting to know the anesthetist who will deliver anesthesia was important to most patients. Furthermore, patients assessed the waiting time, which should be as short as possible, of high priority, as this item was rated the second most important [16].

In general, high satisfaction scores are a very common phenomenon in patient satisfaction surveys (e.g. original ZUF-8 study) [9] [14] [17]. Due to the "satisfaction paradox" (i.e. objectively negative factors only slightly affect patients' perception of quality of life) patients tend to evaluate (medical) services rather positive than negative independent of their current experience with these services [17] [18]. Therefore, different levels of satisfaction are more likely to occur between less and more satisfied patients than between fully satisfied and dissatisfied patients [14] [19]. This can be confirmed by our results with only small differences at high levels of satisfaction in favor of residents. O'Malley et al. revealed that patients of a trainee staff team reported equally high levels of satisfaction compared to patients of faculty staff [20]. Moreover, almost all of the trainees' patients indicated that they would be willing to come to trainee teams again. Particularly the residents' way of communication and their skills in showing personal concern, comforting and listening were appreciated by their patients [21].

Soft skills and a friendly attitude are regarded as very important factors to generate high levels of patient satisfaction. Our results suggest that patients assessed their briefings by residents with a higher level of quality. This might be due to a more patient-centered style of communication. To create such a patient centered communication technique a high level of empathy from the physician seems to be essential [4]. De Maria et al. showed that an empathetic communication technique like the BATHE method (i.e. background, affect, troubling, handling, empathy), originally used in primary care, promotes quality of consultation and can also boost patient satisfaction in the setting of a pre-anesthetic assessment center [5]. Moreover, the combination of a physician's empathetic attitude and a sufficient time to discuss questions tends to reduce anxiety and does increase patient satisfaction during perioperative patient briefing [6]. On the other hand, Schnoor et al. found that a high level of patient satisfaction does not necessarily constitute a low level of concerns patients may hold over anesthetics. Independent of a high level of patient satisfaction a pre-operative consultation mitigated concerns by $23 \%$, whilst for $9 \%$ of all patients this assessment led to a higher level of concerns [12]. However, the residents' excellent results seem to be in contrast to findings of a physician-perceived empathy decline during medical school and residency [7] [8]. The aspects of the "hidden and formal informal curriculum" (i.e. vulnerability, high workload, mistreatment, social support problems, inappropriate learning environment and role models, short hospital stay of patients) might lead to distress during their clinical practice phase [7] [22]. Therefore, residents develop psychological and physiological (i.e. down regulation of mirror neurons) coping strategies to protect themselves, which leads to a frequently observed physician-perceived decline in empathy [7] [8] [23]. 
Nevertheless, both our results and those of other patient satisfaction surveys showed a high level of satisfaction with residents [20] [21] despite a physician-perceived decline in empathy as described in the literature [7] [8]. The level of patient satisfaction seems to be essentially depending on the empathy displayed by the physician [4]. Moreover, Chen et al. showed that serious differences between self-assessment and external assessment are possible and must be considered [24]. In their study medical students' self-perceived empathy decreased during medical school, whereas their observed empathy increased with further clinical training.

Additionally, our results suggest a difference in levels of patient satisfaction regarding residents and consultants with respect to differences in organizational and logistical processes [25]. The estimated time of surgery was known significantly more often by residents than by consultants. A reason could be that the cases handled by residents were less complicated, and thus the estimated time of surgery was easier to predict. This could have led to a higher level of satisfaction of patients briefed by residents.

On the other hand, residents more often indicated missing examination findings. Waiting periods perceived as too long seem to predict lower levels of patient satisfaction [26]. However, our scores of satisfaction did not seem to have been influenced negatively by these factors. Literature provides evidence that consultations that lasted longer than five minutes can balance the negative effect of a longer waiting time on scores of satisfaction in outpatients [27] [28]. Therefore, consulting time might be a stronger predictor of patient satisfaction than waiting time [28]. As our mean consulting time was about sixteen minutes in both groups compared, this might be a possible reason for generally high scores of satisfaction in our survey. However, the influences of organizational and logistical processes on patient satisfaction have not been proven yet and should be investigated in the future.

\section{Limitations}

The pre-anesthetic assessment center is a walk-in clinic. Therefore, immobilized or bedbound patients could not be surveyed in this study. Furthermore, not all patients were included during peak times and out of our services, as additional staff had to be allocated for documentation purposes.

A lack of randomization might have led to a biased survey. Although we did not detect any difference in ASA classification between the groups compared, patients with complex medical conditions might have been more likely assigned to consultants according to clinical routine and routing by nurses.

The presence of an additional person to document organizational and logistical processes could have affected the physicians' kind of consultation further, and might have favored bias by a lack of blinding.

Although a physician's empathy seems to play an important role in the level of satisfaction of the briefed patient, we decided not to collect anesthesiologists' empathy levels, but patient satisfaction, which might be an essential predictor of outcome [2] [4]-[6]. However, due to the "satisfaction paradox" high levels of satisfaction often occur independent of current experiences with any service and thus, false positive results might cause a bias and have to be considered in interpretation [17] [18].

Nevertheless, data demonstrate that residents are able to generate a high level of patient satisfaction. Scores of both residents and consultants ranged between "good" and "very good" and small albeit significant differences in favor of residents underline the quality of their performance in pre-anesthetic patient assessment.

\section{Acknowledgements}

We would particularly like to thank Dr. Dieter Wiegand for his never ending support. Vale!

\section{Financial Support and Sponsorship}

None.

\section{Conflicts of Interest}

None.

\section{References}

[1] Barbosa, C.D., Balp, M.M., Kulich, K., Germain, N. and Rofail, D.A. (2012) A Literature Review to Explore the Link 
between Treatment Satisfaction and Adherence, Compliance, and Persistence. Patient Preference and Adherence, 6, 39-48. http://www.ncbi.nlm.nih.gov/pmc/articles/PMC3262489

[2] Becker, R., Döring, C., Denecke, A. and Brosz, M. (2011) Expectation, Satisfaction and Clinical Outcome of Patients after Total Knee Arthroplasty. Knee Surgery, Sports Traumatology, Arthroscopy, 19, 1433-1441.

http://link.springer.com/article/10.1007\%2Fs00167-011-1621-y http://dx.doi.org/10.1007/s00167-011-1621-y

[3] Schnoor, J., Heydebreck, K., Schuster, S. and Kaisers, U.X. (2012) Patient's Satisfaction within the Scope of Outdoor Anaesthesia and Surgery. Gesundheitökonomie \& Qualitätsmanagement, 17, 192-197. http://dx.doi.org/10.1055/s-0031-1299116

[4] Kim, S.S., Kaplowitz, S. and Johnston, M.V. (2004) Effects of Physician Empathy on Patient Satisfaction and Compliance. Evaluation and the Health Professions, 27, 237-251. http://ehp.sagepub.com/content/27/3/237.long http://dx.doi.org/10.1177/0163278704267037

[5] DeMaria Jr., S., DeMaria, A.P., Silvay, G. and Flynn, B.C. (2011) Use of the BATHE Method in the Preanesthetic Clinic Visit. Anesthesia \& Analgesia, 113, 1020-1026. http://dx.doi.org/10.1213/ANE.0b013e318229497b

[6] Soltner, C., Giquello, J.A., Monrigal-Martin, C. and Beydon, L. (2011) Continuous Care and Empathic Anaesthesiologist Attitude in the Preoperative Period: Impact on Patient Anxiety and Satisfaction. British Journal of Anaesthesia, 106, 680-686. http://bja.oxfordjournals.org/content/106/5/680.full.pdf+html http://dx.doi.org/10.1093/bja/aer034

[7] Neumann, M., Edelhäuser, F., Tauschel, D., Fischer, M.R., Wirtz, M., Woopen, C., Haramati, A. and Scheffer, C. (2011) Empathy Decline and Its Reasons: A Systematic Review of Studies with Medical Students and Residents. Academic Medicine, 86, 996-1009. http://dx.doi.org/10.1097/ACM.0b013e318221e615

[8] Mandel, E.D. and Schweinle, W.E. (2012) A Study of Empathy Decline in Physician Assistant Students at Completion of First Didactic Year. Journal of Physician Assistant Education, 23, 16-24.

[9] Schmidt, J., Lamprecht, F. and Wittmann W.W. (1989) Satisfaction with Inpatient Management. Development of a Questionnaire and Initial Validity Studies. Psychotherapie, Psychosomatik, Medizinische Psychologie, 39, $248-255$.

[10] Attkisson, C.C. and Zwick, R. (1982) The Client Satisfaction Questionnaire. Psychometric Properties and Correlations with Service Utilization and Psychotherapy Outcome. Evaluation and Program Planning, 5, 233-237. http://dx.doi.org/10.1016/0149-7189(82)90074-X

[11] Schmidt, J., Lamprecht, F., Nübling, R. and Wittmann, W.W. (1994) Evaluation of Change by Patients and Staff and Specialist Physicians in Psychosomatic Rehabilitation-A Catamnestic Comparison. Psychotherapie, Psychosomatik, Medizinische Psychologie, 44, 108-114.

[12] Schnoor, J., Reuter, U., Engelmann, N. and Burkhardt, U. (2013) Balance of Concerns: Satisfactory Pre-Anaesthetic Patient Education and the Extent of Patient Worries. Open Journal of Anesthesiology, 3, 402-407. http://dx.doi.org/10.4236/ojanes.2013.39085

[13] Schmidt, J. and Wittmann, W.W. (2002) ZUF-8 Fragebogen zur Messung der Patientenzufriedenheit. In: Brähler, E., Schumacher, J. and Strauß, B., Eds., Diagnostische Verfahren in der Psychotherapie, Hogrefe, Göttingen, 392-396.

[14] Hannöver, W., Dogs, C.P. and Kordy, H. (2000) Patient Satisfaction-A Measure for Success of Treatment? Psychotherapeut, 45, 292-300.

http://journals.ohiolink.edu/ejc/article.cgi?issn $=09356185 \&$ issue $=$ v45i0005\&article $=0292 \_p s a m f s o t$

[15] Beattie, M., Lauder, W., Atherton, I. and Murphy, D.J. (2014) Instruments to Measure Patient Experience of Health Care Quality in Hospitals: A Systematic Review Protocol. Systematic Reviews, 3, 4. http://dx.doi.org/10.1186/2046-4053-3-4

[16] Aust, H., Eberhart, L.H., Kalmus, G., Zoremba, M. and Rüsch, D. (2011) Relevance of Five Core Aspects of the PreAnesthesia Visit: Results of a Patient Survey. Der Anaesthesist, 60, 414-420. http://link.springer.com/article/10.1007\%2Fs00101-010-1828-1 http://dx.doi.org/10.1007/s00101-010-1828-1

[17] Williams, B., Coyle, J. and Healy, D. (1998) The Meaning of Patient Satisfaction: An Explanation of High Reported Levels. Social Science and Medicine, 47, 1351-1359. http://www.sciencedirect.com/science/article/pii/S0277953698002135 http://dx.doi.org/10.1016/S0277-9536(98)00213-5

[18] Herschbach, P. (2002) The "Well-Being Paradox" in Quality-of-Life Research. Psychotherapie, Psychosomatik, Medizinische Psychologie, 52, 141-150. http://dx.doi.org/10.1055/s-2002-24953

[19] Gruyters, T. and Priebe, S. (1994) Evaluation of Psychiatric Treatment by Patients: Results and Problems of Systematic Research. Psychiatrische Praxis, 21, 88-95.

[20] O’Malley, P.G., Omori, D.M., Landry, F.J., Jackson, J. and Kroenke, K. (1997) A Prospective Study to Assess the Effect of Ambulatory Teaching on Patient Satisfaction. Academic Medicine, 72, 1015-1017. 
http://dx.doi.org/10.1097/00001888-199711000-00023

[21] Matthews, D.A., Sledge, W.H. and Lieberman, P.B. (1987) Evaluation of Intern Performance by Medical Inpatients. American Journal of Medicine, 83, 938-944. http://dx.doi.org/10.1016/0002-9343(87)90655-3

[22] West, C.P. and Shanafelt, T.D. (2007) The Influence of Personal and Environmental Factors on Professionalism in Medical Education. BMC Medical Education, 7, 29. http://www.biomedcentral.com/content/pdf/1472-6920-7-29.pdf http://dx.doi.org/10.1186/1472-6920-7-29

[23] Bauer, J. (2005) Warum ich fühle was du fühlst. Intuitive Kommunikation und das Geheimnis der Spiegelneurone. Hoffmann und Campe, Hamburg.

[24] Chen, D.C., Pahilan, M.E. and Orlander, J.D. (2010) Comparing a Self-Administered Measure of Empathy with Observed Behavior among Medical Students. Journal of General Internal Medicine, 25, 200-202. http://link.springer.com/article/10.1007\%2Fs11606-009-1193-4 http://dx.doi.org/10.1007/s11606-009-1193-4

[25] Hepner, D.L., Bader, A.M., Hurwitz, S., Gustafson, M. and Tsen, L.C. (2004) Patient Satisfaction with Preoperative Assessment in a Preoperative Assessment Testing Clinic. Anesthesia \& Analgesia, 98, 1099-1105. http://dx.doi.org/10.1213/01.ANE.0000103265.48380.89

[26] Thompson, D.A., Yarnold, P.R., Williams, D.R. and Adams, S.L. (1996) Effects of Actual Waiting Time, Perceived Waiting Time, Information Delivery, and Expressive Quality on Patient Satisfaction in the Emergency Department. Annals of Emergency Medicine, 28, 657-665. http://www.sciencedirect.com/science/article/pii/S0196064496700902 http://dx.doi.org/10.1016/S0196-0644(96)70090-2

[27] Camacho, F., Anderson, R., Safrit, A., Jones, A.S. and Hoffmann, P. (2006) The Relationship between Patient’s Perceived Waiting Time and Office-Based Practice Satisfaction. North Carolina Medical Journal, 67, 409-413.

[28] Anderson, R.T., Camacho, F.T. and Balkrishnan, R. (2007) Willing to Wait? The Influence of Patient Wait Time on Satisfaction with Primary Care. BMC Health Services Research, 7, 31. http://www.biomedcentral.com/1472-6963/7/31 http://dx.doi.org/10.1186/1472-6963-7-31 


\section{Appendix}

Originally used questionnaire (simplified illustrated and translated into English)

Pre-questionnaire (before consultation)

Have you ever had an anesthetic before (general or regional anesthetic)?

(Yes/No)

You will soon have to undergo surgery. Which of the following statements corresponds mostly to your attitude towards surgery?

(4 = I do not worry about surgery; 3 = I do only little worry about surgery; 2 = I do worry about surgery; 1 = Surgery is a great worry to me)

Your surgery will be performed under anesthesia. Which of the following statements corresponds mostly to your attitude towards anesthesia?

( 4 = I do not worry about anesthesia; 3 = I do only little worry about anesthesia; 2 = I do worry about anesthesia;

$1=$ Anesthesia is a great worry to me)

I have been informed about planned surgery by the surgical department

(Yes/No)

What is your currently highest qualification?

(9 school years/10 school years/High School Diploma/University degree/Completed vocational training/No school qualification)

\section{Process chains and biometric data (filled out by personnel)}

Outpatient/Inpatient

Estimated type of surgery known

(Yes/No)

Estimated time of surgery known

(Yes/No)

Case history known

(Yes/No)

All necessary pre-operative examination findings are available to the anesthesiologist

(Yes/No)

ASA classification

(I/II/III/IV)

Planned anesthetic procedures

(General anesthesia/Spinal or epidural anesthesia/Peripheral neuronal block/Others (combinations out of the others))

The pre-anesthetic consultation was performed by a

(resident/consultant)

Waiting period:.......... (min.)...............Consulting time: (min.)

\section{Post-questionnaire (after consultation)}

In an overall, general sense, how satisfied are you with your pre-anesthetic consultation?

(4 = Very satisfied; 3 = Largely satisfied; 2 = Less satisfied; 1 = Dissatisfied)

Did you get the kind of pre-anesthetic consultation, you wanted?

( 4 = Definitively yes; 3 = Generally yes; 2 = No, not really; 1 = No, definitively not $)$

To what extent has the pre-anesthetic assessment center met your needs?

( 4 = Almost all of my needs have been met; 3 = Most of my needs have been met; 2 = Only a few of my needs have been met; 1 = My needs have not been met)

How would you rate the quality of your pre-anesthetic consultation?

(4 = Excellent; 3 = Good; 2 = Less good; 1 = Bad)

How satisfied are you with the content of your pre-anesthetic consultation?

( 4 = Very satisfied; 3 = Largely satisfied; 2 = Less satisfied; 1 = Dissatisfied $)$

The anesthesiologist was friendly

( 4 = applies completely; 3 = rather applies; 2 = applies less; 1 = does not apply) 
The anesthesiologist advised me well

(4 = applies completely; 3 = rather applies; 2 = applies less; 1 = does not apply)

I have understood the details of anesthesia

(4 = applies completely; 3 = rather applies; 2 = applies less; 1 = does not apply)

The anesthesiologist took enough time for the pre-anesthetic consultation

(4 = applies completely; 3 = rather applies; 2 = applies less; 1 = does not apply)

The anesthesiologist answered all my questions completely

(4 = applies completely; 3 = rather applies; 2 = applies less; 1 = does not apply)

The anesthesiologist spoke to me in a clear language (no technical terms!)

(4 = applies completely; 3 = rather applies; 2 = applies less; 1 = does not apply)

I have understood what the anesthesiologist has discussed with me

( 4 = applies completely; 3 = rather applies; 2 = applies less; 1 = does not apply)

I had to wait too long in the pre-anesthetic assessment center

( 1 = applies completely; 2 = rather applies; 3 = applies less; 4 = does not apply)

If you compare your possible worries about anesthesia prior to the pre-anesthetic consultation with your attitude towards anesthesia now: Which statement is the most likely one?

My worries about anesthesia have been

(4 = Decreased; 3 = Unchanged; 2 = Slightly increased; 1 = Greatly increased)

Has the pre-anesthetic consultation helped you to deal more effectively with your worries about anesthesia?

( 4 = Yes, it helped a great deal; 3 = Yes, it helped a little; 2 = No, it did not really helped; 1 = No, it made things worse to deal with)

If you compare your possible worries about surgery prior to the pre-anesthetic consultation with your attitude towards surgery now: Which statement is the most likely one?

My worries about surgery have been

(4 = Decreased; 3 = Unchanged; 2 = Slightly increased; 1 = Greatly increased)

Has the pre-anesthetic consultation helped you to deal more effectively with your worries about surgery?

( 4 = Yes, it helped a great deal; 3 = Yes, it helped a little; 2 = No, it did not really helped; 1 = No, it made things worse to deal with)

If you needed an anesthetic again, would you come back to the Department of Anesthesia?

(4 = Definitively yes; 3 = Generally yes; 2 = No, not really; 1 = No, definitively not)

If a friend needed an anesthetic, would you recommend the Department of Anesthesia?) to him/her?

(4 = Definitively yes; 3 = Generally yes; 2 = No, not really; 1 = No, definitively not)

If you needed medical attention again, would you come back to the University Hospital Leipzig?

(4 = Definitively yes; 3 = Generally yes; 2 = No, not really; 1 = No, definitively not)

If a friend needed medical attention, would you recommend the University Hospital Leipzig to him/her?

(4 = Definitively yes; 3 = Generally yes; 2 = No, not really; 1 = No, definitively not) 
Scientific Research Publishing (SCIRP) is one of the largest Open Access journal publishers. It is currently publishing more than 200 open access, online, peer-reviewed journals covering a wide range of academic disciplines. SCIRP serves the worldwide academic communities and contributes to the progress and application of science with its publication.

Other selected journals from SCIRP are listed as below. Submit your manuscript to us via either submit@scirp.org or Online Submission Portal.
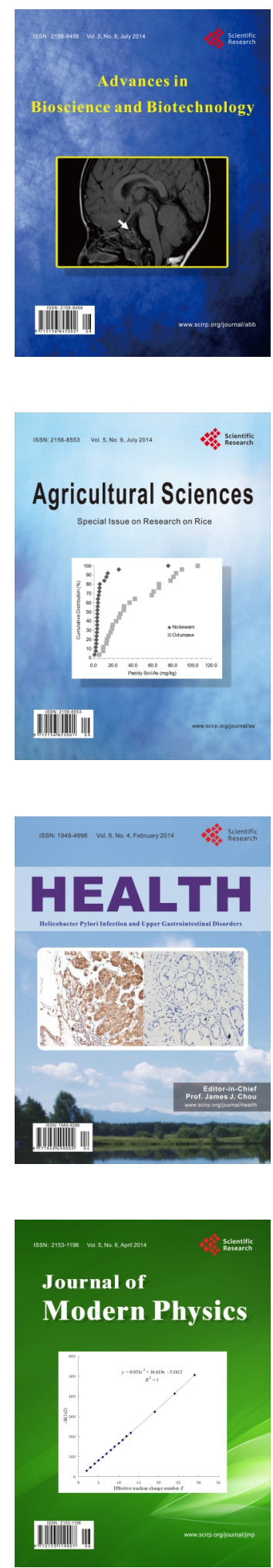
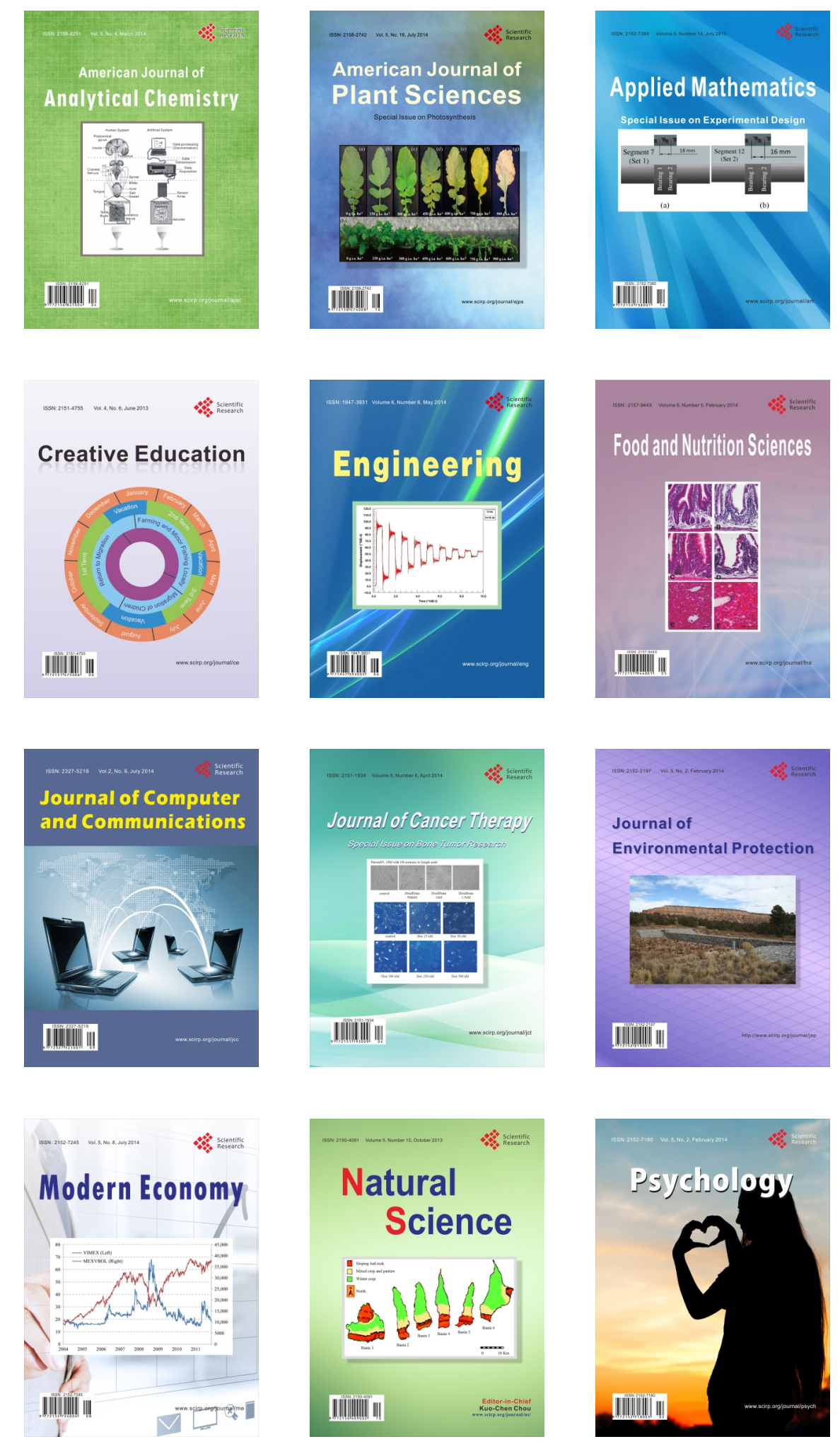